\title{
Connecting Communities for Ecological Restoration
}

\author{
Jim Hallett
}

"Now, here, you see, it takes all the running you can do, to keep in the same place. If you want to get somewhere else, you must run at least twice as fast as that!"

- The Red Queen to Alice in Lewis Carroll's Through the Looking-Glass

$\Gamma^{\prime}$ 'v 've always loved that line, but I appreciate it more since turning my attention to ecological restoration about 12 yr ago. Many of us empathize with Alice in our daily efforts to restore ecological function and services, and our empathy is only heightened as baselines shift due to global change. Fortunately, none of us is in the race alone, and although the kilometer markers might move, progress is being made. But how can we make greater progress in ecological restoration? Two of the answers that I've found are in developing connections among people and in increasing awareness and understanding of ecological restoration.

Attending conferences and workshops is a great way to find out what other people are doing and to share experiences. Participation prevents us from having the tunnel vision that often develops when we are focused on specific, local issues, and which leads us to forget the broader context of our work. The conferences in ecological restoration that I have attended have been extremely energizing because of their shared focus and objectives, and because of the diversity of talents and perspectives that are brought together to achieve success. Some of the best conferences I have attended have been regional ones. The Northwest Chapter of the Society for Ecological Restoration (SERNW.org), like others worldwide, fosters a regional conversation about ecological restoration through conferences, workshops, and publications. SERNW often partners with other associations to host biennial meetings. For example, in May 2012, SERNW will join the British Columbia chapter of the Society for Ecological Restoration (SER) and the Washington/British Columbia chapter of the American Fisheries Society. These partnerships ensure broader engagement on important regional challenges and remind us that we are not working alone.

The membership of SERNW consists of a few hundred individuals from business, academia, nonprofits, government agencies, and tribes. When one considers the overall reach of SERNW through its activities, it includes over 1000 individuals with interests in ecological restoration.

Ecological Restoration Vol. 30, No. 2, 2012

ISSN 1522-4740 E-ISSN 1543-4079

(O2012 by the Board of Regents of the University of Wisconsin System.
In a first step to develop connections within this network, members of the SERNW board categorized the areas of expertise of 994 individuals. Over 24 disciplines are represented from branches of ecology, geology, engineering, design, and social sciences, to planning and permitting. As practitioners, managers, educators, researchers, and students, this group of people represents a great deal of experience which potentially can be shared to improve restoration success and efficiency. Developing linkages in the regional restoration network is one of the ongoing projects of SERNW.

Regional restoration is also informed by work conducted nationally and internationally. SER plays a fundamental role in promoting sound ecological practice and research, and in broadly disseminating information on ecological restoration. I have been working on a group project to revise the SER International Primer on Ecological Restoration (2002, available at SER.org). This document provides perhaps the most frequently used definition of ecological restoration with a succinct summary of its applications and challenges. It does need a facelift to reflect changes over the last $10 \mathrm{yr}$ and to provide a more effective vehicle for introducing the subject. One of the first things we did was to conduct a brief survey to determine how the Primer was being used, what was liked, what could be shed, and what needed to be added. Although the survey was only open for about a week, we received over 275 responses from members of the global community willing to share their experience. The results clearly indicated that the Primer was being used frequently to introduce ecological restoration to administrators, managers, and students. The need for a clear and concise exposition that acknowledges new challenges and reflects current practices was restated many times. The many specific comments will be considered for incorporation as the revision is developed. The new Primer should be available later this year, and it will be better because of the contributions of the restoration community. I'll certainly provide our students and field crews with copies, and I know that they will share their understanding of ecological restoration with the people they encounter in the vicinity of restoration areas in which we work. We hope that the community at large will find this publication useful and make recommendations for additional materials to assist their restoration efforts.

\author{
James G. Hallett, \\ Pacific Northwest Regional Representative, Society for \\ Ecological Restoration
}

